\title{
Polymorphisms in CYP17, COMT, and ESR1 genes in women after menopause and association with bone mineral density
}

\author{
C.G. Gonçalves ${ }^{1}$, B.C. Almeida ${ }^{1}$, C.M. Camargo-Kosugi',2, A.M.M. Costa ${ }^{1}$, \\ I.D.C.G. Silva ${ }^{1}$ and M.A. Haidar ${ }^{1}$ \\ ${ }^{1}$ Laboratório de Ginecologia Molecular e Proteômica, Departamento de Ginecologia, \\ Universidade Federal de São Paulo, São Paulo, SP, Brasil \\ 2Departamento de Otorrinolaringologia e Cirurgia de Cabeça e Pescoço, \\ Universidade Federal de São Paulo, São Paulo, SP, Brasil \\ Corresponding author: C.M. Camargo-Kosugi \\ E-mail: cintiakosugi@gmail.com \\ Genet. Mol. Res. 14 (4): 15802-15810 (2015) \\ Received March 16, 2015 \\ Accepted July 23, 2015 \\ Published December 1, 2015 \\ DOI http://dx.doi.org/10.4238/2015.December.1.32
}

\begin{abstract}
In this study, we evaluated genetic factors related to the mineral density during post-menopause. We evaluated 110 women in the first 5 years post-menopause, without previous hormone replacement therapy. Cytochrome P450 17 (CYP17) (rs743572), catechol-O-methyl transferase (COMT) (rs4680), and estrogen receptor 1 (ESR1) (rs9322331) were examined for the presence of polymorphisms. Clinical data were collected by anamnesis; all patients had the osseous densitometry examined using a lunar instrument to determine mineral osseous densitometry in the lumbar column (L2-L4). CYP17, COMT, and ESR1 genotyping was carried out by polymerase chain reaction with DNA collected from buccal swabs. The average age was 51.96 years. The average weights of the patients in control and osteopenia groups were $70.25 \pm 12.00$ and $62.45 \pm 11.64$, respectively $(P=0.001)$ and body mass index $(P=$ 0.006; control: $29.43 \pm 5.25$; osteopenia: $26.72 \pm 4.57$ ). Related to CYP17 polymorphisms, $28.18 \%$ of women were TT (wild-type homozygous), $60 \%$
\end{abstract}


were TC (heterozygous), and $11.82 \%$ were CC (mutated homozygous). Related to COMT polymorphisms, $53.64 \%$ of women were GG (wild-type homozygous), $37.27 \%$ were GA (heterozygous), and $9.09 \%$ were AA (mutated homozygous). Related to ESR $1,53.64 \%$ of women were CC (wildtype homozygous), $40.91 \%$ were CT (heterozygous), and $5.45 \%$ were TT (mutated homozygous). The ESR1 variant allele was significantly higher in the osteopenia group when compared with women in the normal group $(P$ $=0.02$ ). ESR1 may be associated with low mineral osseous densitometry, while CYP17 and COMT gene polymorphisms were not associated with mineral osseous densitometry.

Key words: Catechol-O-methyl transferase; Cytochrome P450 17; Estrogen receptor 1; Osteoporosis; Polymorphism

\section{INTRODUCTION}

The incidence of osteoporosis is increasing. According to the World Health Organization, $13-18 \%$ of women and $3-6 \%$ of men aged more than 50 years suffer from osteoporosis worldwide (Rosa, 2015), affecting 200 million people (Wu et al., 2013). In Brazil, approximately 10 million people have osteoporosis (http://portalsaude.saude.gov.br). In 2010 alone, 74,000 Brazilians suffered from femur fracture (Rosa, 2015). The risk factors associated with osteoporosis include age, gender, and estrogen deficiency following menopause, and oophorectomy is correlated with a rapid reduction in bone mineral density (BMD) (El-Heis et al., 2013). Osteoporosis is a skeletal disorder characterized by a combination of low BMD and deteriorated microarchitecture, leading to an increase in bone brittleness and fracture susceptibility (Gennari et al., 2005; Stolk et al., 2007). Osteoporotic fractures are associated with substantial morbidity and mortality and are therefore a major health care problem in post-menopausal women (Gennari et al., 2005; Stolk et al., 2007; ElHeis et al., 2013). There are several sites of potential occurrence for osteoporotic fracture including the spine, hip, distal forearm, and proximal humerus (El-Heis et al., 2013). The major determinant of bone strength and osteoporotic fracture risk is BMD (Gennari et al., 2005); BMD decrease can be accelerated by factors such as menopause and insufficient dietary calcium (Yilmaz et al., 2011). Osteoporosis is a polygenic disorder resulting from the interaction of common polymorphic alleles and environmental factors (Somner et al., 2004). There are numerous candidate genes implicated in the determination of BMD and in the pathogenesis of osteoporosis, including those encoding for cytokines, those encoding for calciotropic hormones and their receptors, and those encoding for collagenous and noncollagenous proteins in bones (Gennari et al., 2005).

The gene cytochrome P450 17 (CYP17) is located on chromosome 10q24-q25 (Yilmaz et al., 2011) and encodes the cytochrome P450c17 enzyme, which has both 17a-hydroxylase and 17,20-lyase activities (Somner et al., 2004; Yilmaz et al., 2011; Rai et al., 2014). This protein is important in steroid hormone biosynthesis (Rai et al., 2014). 17 $\alpha$-Hydroxylase is responsible for hydroxylating pregnenolone and progesterone, which are converted to $C_{19}$ steroid precursors of testosterone and estrogen through 17,20-lyase activity (Huber et al., 2002; Somner et al., 2004; Gorai et al., 2007). The products of this reaction, 17a-hydroxypregnenolone and 17a-hydroxyprogesterone, are subsequently metabolized to dehydroepiandrosterone and androstenedione, respectively. Because androstenedione is a major precursor of estradiol, CYP17 
activity has a profound effect on the bioavailability of estradiol. P450c17 is a gatekeeper enzyme of steroid metabolism, regulating what amount of the available pool of pregnenolone/progesterone will be converted to estrogens/androgens or sidelined for cortisol/aldosterone production (Huber et al., 2002; Gorai et al., 2007). The 5'-untranslated region of CYP17 includes a common single nucleotide substitution $(\mathrm{T} \rightarrow \mathrm{C}$ ) located $34 \mathrm{bp}$ upstream of the translation initiation site. This polymorphism (rs743572) creates a potential Sp1-like (CCACC box) binding site, which is thought to increase CYP17 gene expression and androgen biosynthesis and is thought to be associated with higher estrogen and androgen levels (Tofteng et al., 2004; Gorai et al., 2007; Rai et al., 2014). Androgens and estrogens are essential for the development and maintenance of bone mass in women (Stolk et al., 2007). After initial hydroxylation of estrogens by isoenzymes in the cytochrome P450 family, the estrogens are further metabolized by catechol-O-methyltransferase (COMT) into more inactive methoxyestrogens (Ronkainen et al., 2008).

COMT encodes for catechol-O-methyltransferase (Stolk et al., 2007), located on chromosome 22q11.2 (Tofteng et al., 2004), which inactivates circulating catechol-estrogens by catalyzing $\mathrm{O}$-methylation of 2-hydroxylated and 4-hydroxylated estrogens to their methoxy derivatives 2-OH-methoxy-estrogen and 4-OH-methoxy-estrogen, respectively (Tofteng et al., 2004; Stolk et al., 2007). A functional nucleotide change of $G$ to $A$ (rs4680) in exon 4 results in a valine to methionine amino acid transition at codon 158 (Val158Met), leading to thermolability and lower activity of the enzyme (Tofteng et al., 2004; Ronkainen et al., 2008). This slows the metabolism of estradiol and subsequently leads to higher serum levels of estradiol (Huber et al., 2002; Lorentzon et al., 2004). This may increase the availability of estrogen and induce the anabolic effects of this hormone on target tissues such as skeletal muscle (Ronkainen et al., 2008). In addition, the polymorphism has been associated with BMD (Lorentzon et al., 2004) and breast cancer (Warren et al., 2006).

Production of the 2 most abundant and important estrogens, estradiol and estrone, is catalyzed by the cytochrome P450 family. Estradiol is a pleiotropic hormone because the estrogen ligand-receptor complex can act as a nuclear transcription factor for a series of different genes. The estrogen receptor (ER) complex binds to classical response elements in the promoter of a wide variety of target genes and modulates gene transcription by recruiting coactivator and corepressor proteins (Li et al., 2014). Hormonal changes, particularly those altered by estradiol status, may be relevant in bone loss (Klaus et al., 2008). Thus, estradiol is involved in the pathophysiology of a wide variety of diseases, including cancers, atherosclerosis, and osteoporosis (Huber et al., 2002).

Human ER has an important effect on bone mass and bone remodeling (loannidis et al., 2002). The skeletal effects of estrogen are mediated by its binding to specific ERs localized on the cytosolic and nuclear level. These receptors belong to the nuclear receptor hormone superfamily and are ligand-inducible transcription factors (Gennari et al., 2005).

ER is identified by 2 isoforms: ESR1 (estrogen receptor 1) and ESR2, which are members of the steroid/thyroid hormone family of nuclear receptors. Through 2 different pathways, including genomic and non-genomic, they have the same biological effects, including proliferation, growth, apoptosis, differentiation, and angiogenesis, and are encoded by separate genes (Dai et al., 2014). Both ESR1 and ESR2 have been identified in bone turnover based on their effects on osteocytes, in osteoblasts, and in bone marrow stromal cells. Estrogen has direct effects on osteocytes, osteoblasts, and osteoclasts and inhibitory effects by blocking the activation of osteoclasts either directly or via osteoblasts, by suppressing the production of bone resorbing cytokines from osteoblasts, and in T-cells (Cauley, 2014). ESR1 is expressed in chondrocytes, stromal cells, and 
osteoblasts, indicating that both bone and cartilage are regulated by ESR1 (Dai et al., 2014). ESR1 is a 595-amino acid protein encoded by ESR1 and is located on chromosome 6q25.1; ESR1 represents an important functional candidate gene in the regulation of bone health. ESR2 is a 530-amino acid protein encoded by the ESR2 gene on chromosome 14q22-24 (Li et al., 2014). Data from ESR2 knockout mice suggest that gene may play a role in mediating estrogenic action related to bone growth and bone size, but not BMD; the exact role of ESR2 in bone remains unknown (Gennari et al., 2005).

Correct expression of ESR1 in different tissues is likely required for estrogens to have a direct effect on estrogen targets and alterations of the expression of the ESR1, and alterations in ESR1 protein function may have pathological consequences in bone and result in genetic variability (Herrington, 2002). The ESR1 locus contains several polymorphic sites, one of which is located in intron I (rs9322331) and results in an allele change of C to T (Villanova et al., 2006). This polymorphism may be associated with the risk of osteoporosis fractures in post-menopausal women.

\section{MATERIAL AND METHODS}

\section{Study population}

This transversal study included 110 post-menopausal women. The study was approved by the Research Ethics Committee of the Federal University of São Paulo/São Paulo Hospital under the protocol number 1637/06; all participants were personally interviewed and signed informed consent.

The present study enrolled a total of 47 osteopenia patients and 63 healthy controls from the Brazil population. Patients and controls were recruited from the Department of Endocrinology Gynecology of UNIFESP/EPM. Individuals with secondary causes of osteoporosis or bone loss, corticosteroid use, and hormone replacement therapy were excluded. Women who, previously, had a dual-energy X-ray absorptiometry scan in the osteoporosis screening unit, body mass index (BMI) of up to $32 \mathrm{~kg} / \mathrm{m}^{2}$ and, follicle-stimulating hormone values above $35 \mathrm{mlU} / \mathrm{mL}$, estradiol lower than $20 \mathrm{pg} / \mathrm{mL}$, and BMD of the lumbar spine (L2-L4) were included in the study.

\section{Genotyping assay}

Samples were obtained from buccal scrapes using a Cytobrush ${ }^{\circledR}$ (KolplastCi, São Paulo, Brasil), rubbed against the oral mucosal lining, and placed in a test tube containing TrisEDTA buffer. Genomic DNA was purified using the Easy-DNA Kit (Invitrogen, Carlsbad, CA, USA) according to the manufacturer instructions. Briefly, amplifications were carried out in a volume of $25 \mu \mathrm{L}$ using a polymerase chain reaction (PCR) standard master mix (Master Mix, Eppendorf, Hamburg, Germany). PCR was performed in a PTC-100 apparatus (MJ Research, Inc., Waltham, MA, USA). The cycling conditions varied in the annealing temperature: including $57^{\circ}, 60^{\circ}$ and, $54^{\circ} \mathrm{C}$ for CYP17-Mspl, COMT-NlallI, and ESR1-Haelll, respectively). The general PCR conditions were as follows: initial denaturation at $94^{\circ} \mathrm{C}$ for 5 min, 40 cycles of denaturation at $94^{\circ} \mathrm{C}$ for $30 \mathrm{~s}$, annealing (based on each gene polymorphism) for $30 \mathrm{~s}$, polymerization at $72^{\circ} \mathrm{C}$ for 30 or $45 \mathrm{~s}$, and a final extension at $72^{\circ} \mathrm{C}$ for $7 \mathrm{~min}$.

Amplified PCR samples were analyzed by $3 \%$ agarose gel electrophoresis and stained with ethidium bromide. Amplified fragments were digested with the appropriate restriction enzyme. Because the presence or absence of the restriction enzyme recognition site results in 
the formation of restriction fragments of different sizes, allele identification was conducted by agarose gel electrophoresis analysis (EPS1001; Amersham Biosciences, Amersham, UK) and the visualization was conducted under UV light. Documentation was carried out using a Kodak Digital Science 1D system.

\section{Statistical analysis}

Analyses were performed using the SPSS 14.0 (SPSS, Inc., Chicago, IL, USA). To compare qualitative variables, including frequencies and proportions, we used the chi-square test $\left(\chi^{2}\right)$. The CLUMP program (version 2.2) was used to verify differences in the genotype frequencies using Monte Carlo simulations (Sham and Curtis, 1995) when necessary. To calculate the value of odds ratios (ORs) and $95 \%$ confidence intervals $(95 \% \mathrm{Cl})$, binary logistic regression was used. When comparing quantitative data, we used the Student $t$-test. The value of statistical significance was set at $5 \%$ or $\mathrm{P}<0.05$.

\section{RESULTS}

The age of patients ranged $41-63$ years, with a mean age of 51.96 years. Weight ranged from 40.50 to $112 \mathrm{~kg}$, with an average of $66.92 \mathrm{~kg}$. Height ranged from 1.40 to $1.66 \mathrm{~m}$, with an average of $1.54 \mathrm{~m}$. The BMI varied from 20.09 to $52.4 \mathrm{~kg} / \mathrm{m}^{2}$, with an average of $28.27 \mathrm{~kg} / \mathrm{m}^{2}$. BMD of the lumbar spine (L2-L4) ranged from 0.717 to $1.729 \mathrm{~g} / \mathrm{cm}^{2}$, with a mean of $1.11 \mathrm{~g} / \mathrm{cm}^{2}$. According to the studied polymorphisms, for the CYP17 gene, $28.2 \%$ of women were TT (wild-type homozygous), $60 \%$ were TC (heterozygous), and $11.8 \%$ were CC (homozygous mutant). COMT gene polymorphism included 53.6\% GG (wild-type homozygous), $37.3 \%$ GA (heterozygous), and $9.1 \%$ AA (homozygous mutant). For the polymorphism of ESR1, $53.6 \%$ were CC (wild-type homozygous), $40.9 \%$ were CT (heterozygous), and $5.5 \%$ were TT (homozygous mutant).

We observed a significant difference between the osteopenia and normal groups in the weight $(t=-3.42 ; P=0.001)$ and $B M l$ of the subjects $(t=-2.82 ; P=0.006)$ (Table 1$)$. We found an association between the genotype distribution of the ESR1 polymorphism and the development of osteopenia $\left(\chi^{2}=6.14 ; \mathrm{P}=0.046\right)$ (Table 2). The allele frequencies of CYP17 and COMT were not significant $(\mathrm{P}=0.46 ; \mathrm{OR}=1.23 ; 95 \% \mathrm{Cl}=0.71-2.11$ and $\mathrm{P}=0.53 ; \mathrm{OR}=0.82 ; 95 \% \mathrm{Cl}=0.45-1.50$, respectively). The $E S R 1$ allele frequency was significant $(\mathrm{P}=0.02 ; \mathrm{OR}=2.08 ; 95 \% \mathrm{Cl}=1.13-3.84)$, and the presence of a mutant allele was associated with a 2 -fold increased chance of developing osteopenia.

\begin{tabular}{|c|c|c|c|c|c|c|}
\hline Parameter & BMD status & $\mathrm{N}$ & Mean & SD & $t$ & $\mathrm{P}$ \\
\hline \multirow[t]{2}{*}{ Age } & Osteopenia & 47 & 52.62 & 4.16 & 1.44 & 0.15 \\
\hline & Control & 63 & 51.48 & 4.07 & & \\
\hline \multirow[t]{2}{*}{ Weight } & Osteopenia & 47 & 62.45 & 11.64 & -3.42 & 0.001 \\
\hline & Control & 63 & 70.25 & 12.00 & & \\
\hline \multirow[t]{2}{*}{ Height } & Osteopenia & 47 & 1.53 & 0.06 & -1.77 & 0.08 \\
\hline & Control & 63 & 1.55 & 0.05 & & \\
\hline \multirow[t]{2}{*}{ BMI } & Osteopenia & 47 & 26.72 & 4.57 & -2.82 & 0.006 \\
\hline & Control & 63 & 29.43 & 5.25 & & \\
\hline
\end{tabular}

${ }^{\star}$ Osteopenia $=$ BMD values $\leq 1.047$. Control $=$ BMD values $>1.047 \mathrm{mg} / \mathrm{cm}^{2}$. 


\begin{tabular}{|c|c|c|c|c|c|c|}
\hline & $\mathrm{N}(\%)$ & & Genotypes & & $\chi^{2}$ & $P$ \\
\hline CYP17 & & $\mathrm{TT}$ & $\mathrm{TC}$ & $\mathrm{CC}$ & & \\
\hline Osteopenia & 47 & $12(25.53)$ & $28(59.57)$ & 7 (14.89) & 0.86 & 0.65 \\
\hline Control & 63 & $19(30.16)$ & $38(60.32)$ & $6(9.52)$ & & \\
\hline COMT & & GG & GA & $\mathrm{AA}$ & & \\
\hline Osteopenia & 47 & 25 (53.19) & $20(42.55)$ & $2(4.26)$ & 2.73 & 0.26 \\
\hline Control & 63 & $34(53.97)$ & $21(33.33)$ & $8(12.70)$ & & \\
\hline ESR1 & & CC & СT & $\mathrm{TT}$ & & \\
\hline Osteopenia & 47 & $19(40.43)$ & $24(51.06)$ & $4(8.51)$ & 6.14 & 0.046 \\
\hline \multirow[t]{3}{*}{ Control } & 63 & $40(63.49)$ & $21(33.33)$ & $2(3.71)$ & & \\
\hline & & \multicolumn{3}{|c|}{ ESR1 adapted genotypic distribution } & & \\
\hline & & $\mathrm{CC}$ & $\mathrm{CT}+\mathrm{TT}^{*}$ & OR $(95 \% \mathrm{Cl})$ & & \\
\hline Osteopenia & 47 & $19(40.43)$ & 28 (59.57) & $2.56(1.18-5.57)$ & 5.76 & 0.01 \\
\hline Control & 63 & 40 (63.49) & $23(36.51)$ & & & \\
\hline
\end{tabular}

${ }^{*} \mathrm{OR}=$ odds ratio adjusted, homozygous wild $v s$ heterozygous and homozygous mutant. $\mathrm{Cl}=$ confidence interval. $\mathrm{P}$ value as determined by chi-square.

When we included BMI and weight in the logistic regression to control for differences, the association between the ESR1 polymorphism and risk of developing osteopenia was even stronger $(\mathrm{OR}=3.22 ; 95 \% \mathrm{Cl}=1.37-7.58 ; \mathrm{P}=0.007)$.

\section{DISCUSSION}

Osteoporosis is a chronic disease involving multiple factors and is a common disabling age-related disease characterized by reduced BMD, disorganization of skeletal integrity, and microarchitecture. This disease also increases the risk of fragility fractures (Chen et al., 2005; Stolk et al., 2007; El-Heis et al., 2013). Hip and vertebral fractures are also associated with high mortality in the 2 years after the event (Hiligsmann et al., 2013). Sex hormones play a critical role in bone homeostasis, and declining estrogen availability after menopause is a central factor in the development of osteoporosis (Zarrabeitia et al., 2007). BMD is under strong genetic control, where as much as $60 \%$ of the variance in BMD has been attributed to genetic factors (Chen et al., 2005). In addition, the incidence of osteoporosis in elderly people and post-menopausal women is rising as the population ages, adding to the societal problems of health (Wu et al., 2013).

In the present study of post-menopausal women, we analyzed the possible correlations between polymorphisms in CYP17, COMT, and ESR1 and BMD. There was no association with the CYP17 genotype and bone mass $(P=0.65)$. Chen et al. $(2005)$ observed the same results in a study of the correlation between BMD, susceptibility to osteoporosis, and CYP17 polymorphism. Zarrabeitia et al. (2007) also found no association with this single nucleotide polymorphism. However, Somner et al. (2004) failed to demonstrate statistical significance $(P=0.08)$ when comparing the CYP17 polymorphism between control and case groups when examining the association between serum sex steroid concentrations and BMD in post-menopausal women (Somner et al., 2004). Additionally, Tofteng et al. (2004) found that the lumbar spine (L2-L4) cross-sectional area $\left(\mathrm{cm}^{2}\right)$ was reduced in homozygous mutant women in Denmark, but they did not observe a significant difference in the femoral neck, and bone mineral content, BMD, and bone mineral apparent density did not differ by CYP17 genotype. However, Yilmaz et al. (2011) found that the CYP17 gene polymorphism was associated with osteoporosis in post-menopausal women in Turkey, and Yamada et al. (2005) suggested that CYP17 contains susceptibility loci for increased BMD in post-menopausal and pre-menopausal 
Japanese women. In addition, this polymorphism was associated with selected physiochemical factors of uterine leiomyoma, and significant associations between physiochemical factors comprising BMI, waist circumference, and estrogen levels were found to be disease indicators in a black Caribbean population (Alleyne et al., 2014). Additionally, this gene may be associated with an increased risk of gallbladder (Rai et al., 2014) and breast cancers (Chattopadhyay et al., 2014).

Regarding COMT gene polymorphism, we found no statistically significant difference $(\mathrm{P}=$ 0.26) in BMD in post-menopausal women. Tofteng et al. (2004) also found no association with genotype and $\mathrm{BMD}$, bone mineral content, cross-sectional area, or bone mineral apparent density in the lumbar spine or at the femoral neck in post-menopausal women with or without hormone replacement therapy, corroborating our findings. However, Gorai et al. (2007) found that together, the CYP17 and COMT genotypes may exert an effect on bone directly or indirectly by influencing endogenous sex steroids in post-menopausal Japanese women. We found no other studies that showed this possible association in women. However, Stolk et al. (2007) showed that both lumbar spine BMD and femoral neck BMD did not differ by COMT genotype, and they found no association between the COMT polymorphism and serum estrone and estradiol levels in elderly men. In contrast, Eriksson et al. (2008) demonstrated that the COMT Val158Met polymorphism was associated with lifetime fracture prevalence in elderly Swedish men. Lorentzon et al. (2004) showed that the gene polymorphism is associated with peak BMD in men. Additional studies suggest that the single nucleotide polymorphism may affect the susceptibility to wearing-off in Parkinson's disease (Wu et al., 2014), and it may be correlated with cognitive functions in Gilles de la Tourette syndrome (Ji et al., 2015). Moreover, the polymorphism has been correlated with muscle mass properties based on enzyme activity studies (Ronkainen et al., 2008).

The most studied polymorphisms in intron 1 of ESR1 are rs2234693 and rs9340799 (Gennari et al., 2005; Liu et al., 2014), which were found to potentially contribute to or be associated with the pathogenesis of osteoarthritis (Dai et al., 2014; Liu et al., 2014). These sites were associated with low bone mass and low estradiol levels, and it is likely that the allele exerts its influence on the bone in early adulthood, leading to an increased risk of osteoporosis later in life (Jeedigunta et al., 2010). rs9322331 was recently genotyped in an Uppsala Longitudinal Study of Adult Men cohort by Dahlgren et al. (2008), indicating an association between ESR1 and body height in adults males $(P=0.040)$. In this study, we found a significant association between the polymorphism and osteopenia development $(P=0.046)$. The allelic distribution was significantly higher in the osteopenic group compared with the control group $(P=0.02)$. In addition, the presence of the only one variant allele increased the risk of developing osteopenia by 2 -fold $(\mathrm{OR}=2.08 ; 95 \% \mathrm{Cl}=1.13$ 3.84). Nevertheless, when comparing the CC genotype (homozygous wild-type) with genotypes that showed at least one mutated allele (CT and TT), the results suggested that the presence of only one mutated allele could increase for 2-fold the likelihood for the development of the osteopenia $(\mathrm{OR}=2.56 ; 95 \% \mathrm{Cl}=1.18-5.57)$. It is important to highlight that the ESR1 gene polymorphism was associated with osteopenia development in post-menopausal Brazilian women. Little information is available regarding the role of these polymorphisms as risk factors for osteoporosis development, and thus we examined their associations in this study.

An important study performed by Klos et al. (2008) revealed an association between the rs9322331 polymorphism and plasma lipid levels in the Rochester Family Heart Study, which included youths aged 15 years and younger. In contrast, Villanova et al. (2006) found no statistical support to the hypothesis that these polymorphisms could increase the risk of leiomyoma development. ESR1 polymorphism did not differ between leiomyoma and control groups. 
Interestingly, our results suggested that the ESR1 polymorphism might be a relevant biological marker to bone mass loss prevention in women after menopause. However, more analysis is required to examine the genotype and the relationship in post-menopausal women and BMD.

\section{Conflicts of interest}

The authors declare no conflict of interest.

\section{REFERENCES}

Alleyne AT, Austin S and Williams A (2014). Distribution of CYP17a polymorphism and selected physiochemical factors of uterine leiomyoma in Barbados. Meta Gene 2: 358-365.

Cauley JA (2014). Estrogen and bone health in men and women. Steroids 99: 11-15.

Chattopadhyay S, Siddiqui S, Akhtar MS, Najm MZ, et al. (2014). Genetic polymorphisms of ESR1, ESR2, CYP17A1, and CYP19A1 and the risk of breast cancer: a case control study from North India. Tumour Biol. 35: 4517-4527.

Chen HY, Chen WC, Hsu CM, Tsai FJ, et al. (2005). Tumor necrosis factor alpha, CYP 17, urokinase, and interleukin 10 gene polymorphisms in postmenopausal women: correlation to bone mineral density and susceptibility to osteoporosis. Eur. $J$. Obstet. Gynecol. Reprod. Biol. 122: 73-78.

Dahlgren A, Lundmark P, Axelsson T, Lind L, et al. (2008). Association of the estrogen receptor 1 (ESR1) gene with body height in adult males from two Swedish population cohorts. PloS One 3: e1807.

Dai X, Wang C, Dai J, Shi D, et al. (2014). Association of single nucleotide polymorphisms in estrogen receptor alpha gene with susceptibility to knee osteoarthritis: a case-control study in a Chinese Han population. Biomed. Res. Int. 2014: 151457.

El-Heis MA, Al-Kamil EA, Kheirallah KA, Al-Shatnawi TN, et al. (2013). Factors associated with osteoporosis among a sample of Jordanian women referred for investigation for osteoporosis. EMHJ 19: 459-464.

Eriksson AL, Mellström D, Lorentzon M, Orwoll ES, et al. (2008). The COMT val158met polymorphism is associated with prevalent fractures in Swedish men. Bone 42: 107-112.

Gennari L, Merlotti D, De Paola V, Calabrò A, et al. (2005). Estrogen receptor gene polymorphisms and the genetics of osteoporosis: a HuGE review. Am. J. Epidemiol. 161: 307-320.

Gorai I, Inada M, Morinaga H, Uchiyama Y, et al. (2007). CYP17 and COMT gene polymorphisms can influence bone directly, or indirectly through their effects on endogenous sex steroids, in postmenopausal Japanese women. Bone 40: 28-36.

Herrington DM (2002). Estrogen-receptor polymorphisms and effects of estrogen replacement on high-density lipoprotein cholesterol in women with coronary disease. N. Engl. J. Med. 346: 967-974.

Hiligsmann M, Kanis JA, Compston J, Cooper C, et al. (2013). Health technology assessment in osteoporosis. Calcif. Tissue Int. 93: 1-14.

Huber JC, Schneeberger C and Tempfer CB (2002). Genetic modelling of the estrogen metabolism as a risk factor of hormonedependent disorders. Maturitas 42: 1-12.

Ioannidis JPA, Stavrou I, Trikalinos TA, Zois C, et al. (2002). Association of polymorphisms of the estrogen receptor alpha gene with bone mineral density and fracture risk in women: a meta-analysis. J. Bone Miner. Res. 17: 2048-2060.

Jeedigunta Y, Bhoomi Reddy PR, Kolla VK, Munshi A, et al. (2010). Association of estrogen receptor alpha gene polymorphisms with BMD and their effect on estradiol levels in pre- and postmenopausal women in south Indian population from Andhra Pradesh. Clin. Chim. Acta 411: 597-600.

Ji W, Li N, Ju K, Zheng H, et al. (2015). Association of catechol-O-methyltransferase val/met polymorphism with cognitive function in Gilles de la Tourette syndrome patients. Neurol. Sci. 36: 561-570.

Klaus J, Reinshagen M, Adler G, Boehm B, et al. (2008). Bones and Crohn's: estradiol deficiency in men with Crohn's disease is not associated with reduced bone mineral density. BMC Gastroenterol. 8: 48.

Klos KLE, Boerwinkle E, Ferrell RE, Turner ST, et al. (2008). ESR1 polymorphism is associated with plasma lipid and apolipoprotein levels in Caucasians of the Rochester Family Heart Study. J. Lipid Res. 49: 1701-1706.

Li TF, Wu QY, Zhang C, Li WW, et al. (2014). Polymorphisms in estrogen receptors predict the risk of male infertility: a metaanalysis. Reprod. Biol. Endocrinol. 12: 79.

Liu W, Shao F, Yan L, Cao H, et al. (2014). Polymorphisms in the gene encoding estrogen receptor alpha are associated with osteoarthritis in Han Chinese women. Int. J. Exp. Med. 7: 5772-5777.

Lorentzon M, Eriksson AL, Mellström D and Ohlsson C (2004). The COMT val158met polymorphism is associated with peak BMD in men. J. Bone Miner. Res. 19: 2005-2011. 
Rai R, Sharma KL, Misra S, Kumar A, et al. (2014). CYP17 polymorphism (rs743572) is associated with increased risk of gallbladder cancer in tobacco users. Tumour Biol. 35: 6531-6537.

Ronkainen PHA, Pöllänen E, Törmäkangas T, Tiainen K, et al. (2008). Catechol-o-methyltransferase gene polymorphism is associated with skeletal muscle properties in older women alone and together with physical activity. PLoS One 3: e1819.

Rosa P (2015). Prevenção à osteoporose deve começar na infância. In: Portal da saúde - Ministério da Saúde. [http:// portalsaude.saude.gov.br/index.php/cidadao/principal/saude-em-dia/mais-sobre-saude-em-dia]. Accessed January 13, 2015.

Sham PC and Curtis D (1995). Monte Carlo tests for associations between disease and alleles at highly polymorphic loci. Ann. Hum. Genet. 59: 97-105.

Somner J, McLellan S, Cheung J, Mak YT, et al. (2004). Polymorphisms in the P450 c17 (17-hydroxylase/17,20-lyase) and P450 c19 (aromatase) genes: association with serum sex steroid concentrations and bone mineral density in postmenopausal women. J. Clin. Endocrinol. Metab. 89: 344-351.

Stolk L, van Meurs JBJ, Jhamai M, Arp PP, et al. (2007). The catechol-O-methyltransferase Met158 low-activity allele and association with nonvertebral fracture risk in elderly men. J. Clin. Endocrinol. Metab. 92: 3206-3212.

Tofteng CL, Abrahamsen B, Jensen JEB, Petersen S, et al. (2004). Two single nucleotide polymorphisms in the CYP17 and COMT genes - relation to bone mass and longitudinal bone changes in postmenopausal women with or without hormone replacement therapy. The Danish Osteoporosis Prevention Study. Calcif. Tissue Int. 75: 123-132.

Villanova FE, Andrade PM, Otsuka AY, Gomes MTV, et al. (2006). Estrogen receptor alpha polymorphism and susceptibility to uterine leiomyoma. Steroids 71: 960-965.

Warren R, Skinner J, Sala E, Denton E, et al. (2006). Associations among mammographic density, circulating sex hormones, and polymorphisms in sex hormone metabolism genes in postmenopausal women. Cancer Epidemiol. Biomarkers Prev. 15: 1502-1508.

Wu H, Dong F, Wang Y, Xiao Q, et al. (2014). Catechol-O-methyltransferase Val158Met polymorphism: modulation of wearingoff susceptibility in a Chinese cohort of Parkinson's disease. Parkinsonism Relat. Disord. 20: 1094-1096.

Wu X, Guo S, Shen G, Ma X, et al. (2013). Screening of osteoprotegerin-related feature genes in osteoporosis and functional analysis with DNA microarray. Eur. J. Med. Res. 18: 15.

Yamada Y, Ando F and Shimokata H (2005). Association of polymorphisms in CYP17A1, MTP, and VLDLR with bone mineral density in community-dwelling Japanese women and men. Genomics 86: 76-85.

Yilmaz MB, Pazarbasi A, Guzel Al, Kocaturk-Sel S, et al. (2011). Association of serum sex steroid levels and bone mineral density with CYP17 and CYP19 gene polymorphisms in postmenopausal women in Turkey. Genet. Mol. Res. 10: 1999-2008.

Zarrabeitia MT, Hernandez JL, Valero C, Zarrabeitia A, et al. (2007). Adiposity, estradiol, and genetic variants of steroidmetabolizing enzymes as determinants of bone mineral density. Eur. J. Endocrinol. 156: 117-122. 